\title{
А.А. КАБУРКИН
}

\section{СУДЫ ХАНТЫ-МАНСИЙСКОГО АВТОНОМНОГО ОКРУГА В ПЕРВЫЙ ГОД ПОСЛЕВОЕННОЙ ПЯТИЛЕТКИ}

\begin{abstract}
Ключевые слова: Великая Отечественная война, Ханты-Мансийский национальный округ, Тюменская область, Ханты-Мансийский автономный округ, Югра, послевоенная пятилетка, восстановление народного хозяйства, суд, судебная система, органы советской власти, карательная политика.
\end{abstract}

Судебная система и судебная власть в любом государстве и в любом обществе выполняют весьма важные общественно значимые функции. Именно поэтому вопросы становления, формирования, а также нормативно-правового регулирования системы судопроизводства, совершенствования законодательной основы деятельности судебной системы являются серьезным звеном в построении демократического правового государства. Всестороннее и полное изучение строительства и трансформации советской судебной системы в таком разрезе чрезвычайно актуально и имеет для российского общества и для российского государства первостепенное значение, так как именно система советского судопроизводства явилась основой для построения действующей ныне российской системы судопроизводства. В таком аспекте послевоенный этап формирования судебной системы в СССР вызывает особый интерес, его исследование требует особо тщательного внимания и детального анализа, в том числе в силу оригинальности и уникальности в разрезе мировой истории. В статье рассмотрены особенности формирования и деятельности судебных органов Ханты-Мансийского национального округа, а также проблемы, с которыми столкнулись суды округа после окончания Великой Отечественной войны в первый год послевоенной пятилетки 1946-1950-х г2., направленной на восстановление народного хозяйства. Показаны специфика и своеобразие фрункционирования системы судебных органов округа, отражены основные направления, на которые суды округа направили свои усилия, описаны главные проблемы, с которыми суды столкнулись в своей работе. Представлены статистические данные по ключевым позициям, характеризующим как уголовную судебно-карательную политику, так и производство по гражданско-правовому направлению. Приведены недостатки в деятельности советской судебной системы на территории округа. Отмечено, что суды внесли существенный вклад в восстановление народного хозяйства и налаживание мирной жизни региона. Несмотря на наличие определенных проблем в деятельности судов округа, вопреки трудностям в работе, связанным в том числе с географрическими особенностями округа, судебные органы обеспечили исполнение возложенных на них крайне важных задач в области как осуществления правосудия, так и обеспечения карательной политики и, соответственно, следования политике партии. При этом, невзирая на увеличение преступности в первый послевоенный год, рост уголовных дел, суды округа улучшили качество рассмотрения дел.

Великая Отечественная война, как величайшее потрясение и испытание XX в., самым кардинальным образом изменила историю советского государства, существенно отразилась на всех сторонах советского общества, в том числе на советской судебной системе. 
Органы советской власти, включая суды, в период войны наглядно показали свою способность организовать общество для защиты страны от внешнего врага, переориентировать экономику на производство продукции для военной промышленности, поднять боевой дух населения.

В послевоенное время перед советским государством стояли уже совсем другие задачи, первоочередными из которых были восстановление и развитие народного хозяйства страны. Эти цели были сформулированы И.В. Сталиным 9 февраля 1946 г. в его речи на предвыборном собрании избирателей в городе Москве как основная хозяйственно-политическая задача четвёртой пятилетки 1946-1950 гг. [6. Л. 5-16].

Послевоенное строительство мирной жизни в Советском Союзе заложило основы современного облика Российской Федерации. Произошли изменения в структуре государственных органов и формах руководства народным хозяйством. В сентябре 1945 г. был упразднен ГКО (Государственный Комитет Обороны), все функции по управлению страной сосредоточились в руках Совета Народных Комиссаров (в марте 1946 г. преобразован в Совет Министров СССР). Как и раньше, фактического разделения ветвей власти не было, все принципиально важные решения принимались под диктатом Коммунистической партии. Культ личности И.В. Сталина достиг своего апогея. Перестройка народного хозяйства и общественной жизни применительно к условиям мирного времени завершилась в основном в 1946 г.

Вопросы послевоенного строительства советского государства имеют весьма актуальное значение. Особый интерес и значение данного периода важно ввиду его преломления на настоящую действительность.

Процессы государственного строительства в современной России продолжаются по настоящий момент, о чем свидетельствуют постоянные изменения в российском законодательстве.

В связи с этим фрормирование советского общества и советского государства после Великой Отечественной войны представляет немаловажный интерес как в целом с исторической точки зрения, так и с точки зрения анализа происходивших в тот период процессов, поиска ошибок и просчетов в принятых ранее решениях, изучения вопросов прошлого в спектре нынешней реальности, а также решения тех или иных проблем, возникающих в современных условиях.

Изучение судебной системы Российской Федерации, истории ее зарождения, становления, фрормирования, фрункционирования, включая развитие и деятельность системы судопроизводства Союза Советских Социалистических Республик, представляет значительный интерес. Актуальность и важность изучения судебной системы обусловливаются теоретической и практической значимостью, ценностью данного вопроса для любого нынешнего общества, так как суды любой страны играют важную роль в развитии гражданского общества и правового государства, а система судопроизводства присутствует во всех государствах.

Актуальность темы, связанной с судебной системой и охватывающей период начала послевоенной (четвертой) пятилетки, связана с тем, что, начавшись с 1990-х гг., процесс рефрормирования системы судов и судопроизводства в Российской Федерации до сих пор не завершен, он продолжается и в данный момент, свидетельством тому являются частые изменения в зако- 
нодательстве, затрагивающие как структуру судов, так и нормативно-процессуальную базу их функционирования.

Принципы и традиции, сорормировавшиеся в рассматриваемый период, в любом случае оказывают определенное влияние на работу нынешнего российского суда и работающих сегодня судебных работников. Разрешение современных проблем системы судопроизводства без тщательного и детального изучения исторического наследия невозможно.

В этом отношении заслуживает внимания судебная система одного из крупнейших регионов страны - Ханты-Мансийского автономного округа - Югры.

Опыт деятельности правоохранительных органов и судопроизводства в Ханты-Мансийском автономном округе представляет особый интерес как малоисследованная проблема, что связано с историческими, географическими, экономическими и иными фракторами, присущими данному региону.

Таким образом, изучение опыта деятельности судебной системы в ХантыМансийском автономном округе в 1946 г. дает возможность более глубокого изучения государственности нашей страны. Тема статьи еще более актуализируется за счет такого ее аспекта, как судебная система, так как этот вопрос в советский период затрагивать было опасно и практически невозможно.

При этом тема заслуживает внимания еще и за счет того, что ХантыМансийский автономный округ - Югра, как указано выше, является одним из крупнейших регионов России, имеет высокий уровень жизни, низкий уровень преступности. Можно отметить при этом, что субъект по многим показателям является одним из ведущих в стране.

Необходимо отметить, что крупный вклад в изучение истории судебной системы Ханты-Мансийского автономного округа внес Д.Н. Шкаревский, изучавший как в целом формирование и функционирование судов округа, так и детально рассматривавший отдельные направления их деятельности, в частности, особенности уголовного и гражданского судопроизводства, кадровый состав [2, 3].

Здесь также нужно обратить внимание на труды А.Я. Кодинцева, который изучал как в целом политико-экономическое развитие регионов, включая Западную Сибирь, так и отдельно органы советской юстиции в послевоенный период $[2-5,8]$. При этом имеются работы об органах правосудия округа, совместно составленные Д.Н. Шкаревским и А.Я. Кодинцевым [2, 3]. В контексте историографии проблемы можно обозначить работы Д.Ю. Михеева [7], который изучал суды Сибири довоенного периода.

Судебные органы в послевоенном Союзе ССР должны были сыграть важную роль в достижении поставленных перед четвертой пятилеткой задач. Жестко регламентированная трудовая деятельность строго охранялась законодательством, а суды должны были обеспечивать неукоснительное соблюдение советских законов под страхом уголовного наказания. Были осуществлены меры, направленные на возобновление нормального режима труда на предприятиях и в учреждениях. Отменялись обязательные сверхурочные работы, восстанавливались 8-часовой рабочий день и ежегодные оплачиваемые отпуска. Сокращались ассигнования на военное производство и увеличивались расходы на развитие мирных отраслей экономики.

Например, в докладе Ханты-Мансийского окружного суда за 1946 г. отмечается, что особенно большие и ответственные задачи стояли перед окружным судом и судами региона в области охраны политических, трудовых, 
жилищных и иных личных и имущественных прав и интересов граждан, установленных Конституцией СССР и Конституцией РСФСР.

Данные по рассмотрению окружным судом уголовных дел за 1946 г. выглядят следующим образом: в суд округа в 1946 г. поступило 95 уголовных дел, при этом 13 уголовных дел оставались в производстве суда с предыдущего года; в течение 1946 г. было рассмотрено 93 дела и остаток на 1 января 1947 г. составил 16 уголовных дел; при этом 9 дел было возвращено на доследование; большую часть (76 дел) занимали уголовные дела, возбужденные по ст. 58-10, 58-1а Уголовного кодекса РСФСР (далее - УК РСФСР), т.е. дела, предусматривающие ответственность за контрреволюционную деятельность [1. Л. 11].

В докладе суда округа отмечался рост преступности по данной категории по сравнению с 1945 г. (в 1945 г. таких дел было 40). Рост преступности объясняется тем, что после Великой Отечественной войны население округа пополнилось спецпереселенцами-калмыками из Калмыцкой АССР и сектантами (называвшими себя «истинно-православными христианами») из Рязанской области, а также спецпереселенцами из демобилизованных с фронта военнослужащих, в чем-то переступивших закон. По остальным категориям уголовных дел отмечалось снижение преступности [1. Л. 11].

Однако в докладе суда отмечалось ухудшение качества следствия по сравнению с 1945 г., в особенности по делам, расследуемыми органами МВД. Это обстоятельство подтверждается такими данными: в 1945 г. с судебного заседания на доследование было возвращено 2 дела, в том числе по ст. 58-10 ч. 2 УК РСФСР одно дело, а в 1946 г. возвращено на доследование девять дел, в том числе по ст. 58-10 ч. 2 УК РСФСР пять дел и по ст. 58-1а УК РСФСР одно дело. Прокурор участвовал в судебных заседаниях на 83 делах и не участвовал по 10 делам [1. Л. 11].

Анализ сроков рассмотрения дел судом округа показывает, что окружным судом дела рассматривались долго, в большие сроки. Причина этого обстоятельства, как и на всем протяжении деятельности судебных органов округа, заключается в том, что округ территориально был велик, а большинство дел поступало из районов, следовательно, судьям приходилось выезжать в районы за сотни километров для рассмотрения уголовных дел.

В то же время у судов округа имелась проблема в финансировании их деятельности. Так, с октября 1946 г. по декабрь 1946 г. абсолютно не финансировались суды округа Управлением Министерства юстиции по Тюменской области. Несмотря на запросы, не поступало ответов до тех пор, пока суд округа не обратился в Министерство юстиции РСФСР, и только после этого им перечислили деньги. Все это отражалось на сроках рассмотрения дел, в связи с чем имел место большой процент дел со сроками их рассмотрения свыше одного месяца.

Относительно сроков рассмотрения уголовных дел Окружным судом можно отметить следующее: в срок свыше 1 месяца было рассмотрено 58 уголовных дел, что составило 63\% от всех рассмотренных дел, в срок от 11 дней до 1 месяца - 27 (29,3\%), до 5 дней включительно - 2 (2,3\%) [1. Л. 12].

Сведения о карательной политике государства свидетельствуют о том, что высшая мера наказания была применена по двум делам, в отношении 66 осужденных назначено наказание в виде лишения свободы от 5 до 9 лет, в отношении 30 лиц - свыше 10 лет, в отношении 33 лиц - до 5 лет [1. Л. 13]. 
Кроме того, в отношении 114 лиц было применено наказание в виде лишения избирательных прав, в отношении 114 граждан - в виде конфискации имущества. Условное наказание было назначено всего лишь трем гражданам [1. Л. 13].

Кассационная практика за 1946 г. по делам, рассмотренным Верховным судом РСФСР, характеризуется следующими данными: всего обжаловано приговоров в отношении 51 человека, из них оставлено в силе - 46 дел, или 91,9\%, отменено во время предварительного следствия - два, или 3,1\%, отменено во время судебного следствия - два, или 3,1\%, прекращено производство - одно, или 1,9\% [1. Л. 14].

Учитывая такое количество оставленных в силе приговоров, а именно свыше 91,9\%, можно резюмировать, что суды округа достигли значительного качества в рассмотрении уголовных дел.

Однако анализ кассационной практики окружного суда свидетельствует о том, что районные суды недостаточно квалифицированно рассматривали уголовные дела. Так, в течение 1946 г. было рассмотрено по второй инстанции уголовных дел в отношении 295 человек, из которых приговор оставлен в силе только в отношении 141 человека. Были прекращены дела с отменой приговоров в отношении 39 человек, что свидетельствует о том, что народные суды незаконно привлекали к уголовной ответственности достаточно большое количество граждан. Кроме того, в отношении 70 лиц приговоры были отменены с передачей дел на новое рассмотрение как со стадией предварительного следствия, так и со стадией судебного следствия, в отношении 45 человек были изменены обвинение и приговор как с переквалификацией статей, так и без переквалификации. Это говорит о том, что более половины приговоров районных судов окружной суд счел незаконными [1. Л. 15].

Анализ статистических сведений кассационной практики по уголовным делам Ханты-Мансийского окружного суда за 1946 г. в разрезе районных народных судов выглядит следующим образом: из восьми народных судов наибольшее количество оставленных в силе приговоров отмечалось по судам Микояновского района и 1-го участка Самаровского района $(61,9 \%$ и $60 \%$, соответственно), затем по убывающей идут суды 2-го участка Кондинского района, 2-го участка Самаровского района, Сургутского района, 1-го участка Кондинского района, Березовского района, Ларьякского района, причем у каждого из них оставлено в силе было менее половины дел [1. Л. 16].

Анализ прекращенных уголовных дел в кассационной инстанции показывает, что максимальный процент таких дел был у суда Березовского района $27,6 \%$, затем у Сургутского народного суда. В целом по округу показатель оставленных в силе решений составил $47,4 \%$, а прекращенных - $11,1 \%$ от всех рассмотренных [1. Л. 16].

Сравнение с 1945 г. показывает, что суды округа в 1946 г. работали значительно хуже, так как в 1945 г. по округу было оставлено в силе 60,5\% приговоров, а в 1946 г. - только 47,4\%.

Документы окружного суда свидетельствуют об увеличении уголовных преступлений за 1946 г.: если за 1945 г. коллегией было рассмотрено 222 уголовных дела, то в 1946 г. - 295. Вместе с тем участие прокурора в заседании суда значительно улучшилось: если в 1945 г. прокурор принимал участие в работе $58,2 \%$ заседаний, то в 1946 г. - в 89,5\%.

Значительный процент отмененных приговоров можно объяснить тем, что народные судьи округа недостаточно квалифицированно готовились 
к заседаниям, принимали к производству дела от следственных органов на граждан, в действиях которых не имелось состава уголовно наказуемого деяния, т.е. на совершенно безвинных людей.

Например, коллегией окружного суда за 1946 г. вовсе было прекращено 37 уголовных дел (11,1\%), приговоры отменены со стадии предварительного следствия в отношении 20 человек (6\%). Причины неудовлетворительной работы народных судов округа можно объяснить еще и тем, что Управление Министерства юстиции по Тюменской области недостаточно грамотно руководило работой судов. В 1946 г. в Ханты-Мансийском автономном округе окружным судом была проведена ревизия работы четырех народных судов. В результате ревизии были вскрыты серьезные недостатки в работе судов, вплоть до нарушения революционной законности. Но Управление Министерства юстиции своевременно никаких мер не приняло, даже ни по одному акту ревизии не было издано приказа, в котором было бы обращено внимание на допущенные ошибки.

Таким образом, приведенные выше материалы свидетельствуют о том, что судебная система Ханты-Мансийского автономного округа в 1946 г. не вполне удовлетворительно справлялась со своими обязанностями по защите прав, свобод, имущества и безопасности жителей, значит, прежде всего, она выполняла карательные функции. На это есть субъективные и объективные причины: субъективные причины - недостаточная юридическая грамотность работников судов, халатное отношение к возложенным обязанностям, определенный конформизм самих жителей, т.е. обвиняемых; объективные - недостаточное финансовое обеспечение работников судов, большая протяженность территории округа, нехватка кадров квалифицированных работников, увеличение численности населения за счет демобилизованных с фронта военнослужащих, перегруженность судов уголовными делами, жесткая репрессивная политика государства против своих граждан.

Литература

1. Государственный архив Ханты-Мансийского автономного округа - Югры. Ф. 180. Оп. 1. Д. 12.

2. Кодинцев А.Я., Шкаревский Д.Н. Органы правосудия ХМАО-Югры в 1930-1950е годы. Сургут: Библиографика, 2019. 188 с.

3. Кодинцев А.Я., Шкаревский Д.Н., Яноши В.В. Органы специальной юстиции СССР в 1930-1950-е годы: коллективная монография. Сургут: Изд. центр СурГУ, 2016. 254 с.

4. Кодинцев А.Я. Органы специальной юстиции в СССР в 1920-1950-е годы: историография // Транспортное право. 2020. № 2. С. 29-32.

5. Кодинцев А.Я. Современная историография советского судоустройства в 1930 1950-е годы // Российский судья. 2020. № 1. С. 59-64.

6. Сталин И.В. Сочинения. М.: Писатель, 1997. Т. 16. 466 с.

7. Михеев Д.Ю. Суды Сибири в 1928-1938 гг. Новосибирск: Новосибирский военный ин-т внутренних войск им. И.К. Яковлева, 2015. 124 с.

8. Кодинцев А.Я. Теория судебного управления в России во второй половине XX века // Управление в правоохранительной сфере: траектория развития. Челябинск: Изд. центр ЮУрГУ, 2019. С. 6-23.

КАБУРКИН АЛЕКСАНДР АЛЕКСАНДРОВИЧ - аспиранТ кафедры отечественной истории, Чувашский государственный университет, Россия, Чебоксары (kaa21.777@yandex.ru; ORCID: https://orcid.org/0000-0002-4597-7996). 


\title{
Aleksandr A. KABURKIN \\ COURTS OF THE KHANTY-MANSI AUTONOMOUS OKRUG IN THE FIRST YEAR OF THE POST-WAR FIVE-YEAR PLAN
}

\begin{abstract}
Key words: the Great Patriotic War, Khanty-Mansi National District, Tyumen Region, Khanty-Mansi Autonomous District, Ugra, post-war five-year plan, restoration of the national economy, court, judicial system, Soviet authorities, punitive policy.
\end{abstract}

The judicial system and the judicial authority in any state and in any society perform very important socially significant functions. That is why the issues of evolvement, formation, as well as the legal regulation of the court system, improving the legislative framework of the judicial system's activity are a serious link in the construction of a democratic state governed by the rule of law. A comprehensive and complete study of construction and transformation of the Soviet judicial system in this context is extremely relevant and is of paramount importance both for the Russian society and for the Russian state, since it was the Soviet judicial system that was the basis for constructing the current Russian judicial system. In this aspect, the post-war stage in the formation of the judicial system in the USSR is of particular interest, its study requires a particularly careful attention and detailed analysis, including due to its originality and uniqueness in the context of world history. The article considers the features of the formation and activity of the judicial bodies in the Khanty-Mansi National District, as well as the problems faced by the district courts after the end of the Great Patriotic War in the first year of the post-war five-year plan of 1946-1950, aimed at restoring the national economy. The article shows the specifics and uniqueness of the district judicial system functioning, reflects the main directions to which the district courts directed their efforts, describes the main problems that the courts faced in their work. The article presents statistical data on key positions that characterize both criminal judicial and punitive policy and civil law proceedings. Problems and shortcomings in the activity of the Soviet judicial system in the territory of the district are reflected. It is noted that the courts made a significant contribution to the national economy restoration and the establishment of peaceful life in the region. Despite the existence of certain problems in the activities of the district courts, despite the difficulties in their work, including due to the geographical features of the district, the judicial authorities ensured the fulfillment of their extremely important tasks in the field of both administration of justice and ensuring punitive policies and, consequently, following the party's policies. At this, despite the increase in crime in the first post-war year, the growth of criminal cases, the district courts improved the quality of proceedings conduct.

\section{References}

1. Gosudarstvennyi arkhiv Khanty-Mansyiskogo avtonomnogo okruga - Ugra. Fond 180. Opis' 1. Delo 1 [State Archive of the Khanty-Mansi Autonomous District - Ugra. Archives 180. Anagraph 1. Document 12].

2. Kodintsev A.Ya., Shkarevskiy D.N. Organy pravosudiya KhMAO-Yugry v 19301950-e gody [The bodies of justice of the Khanty-Mansi Autonomous Okrug-Yugra in the 1930s-1950s]. Surgut, Bibliography Publ., 2019, 188 p.

3. Kodintsev A.Ya., Shkarevskiy D.N., Yanoshi V.V. Organy spetsial'noy yustitsii SSSR $v$ 1930-1950-e gody [Bodies of special justice of the USSR in the 1930s-1950s]. Surgut, 2016, 254 p.

4. Kodintsev A.Ya. Organy spetsial'noy yustitsii v SSSR v 1920-1950-e gody: istoriografiya [Bodies of special justice in the USSR in the 1920s-1950s]. Transportnoe parvo, 2020, no. 2, pp. 29-32. 
5. Kodintsev A.Ya. Sovremennaya istoriografiya sovetskogo sudoustroystva v 19301950-e gody [Modern historiography of the Soviet judicial system in the 1930-1950s]. Rossiyskiy sud'ya, 2020, no. 1, pp. 59-64.

6. Stalin I.V. Cochineniya [Works]. Moscow, Pisatel Publ., 1997, vol. 16, 466 p.

7. Mikheev D.Yu. Sudy Sibiri v 1928-1938 gg. [Courts of Siberia in 1928-1938]. Novosibirsk, 2015, 124 p.

8. Kodintsev A.Ya. Teoriya sudebnogo upravleniya $v$ Rossii vo vtoroy polovine KhKh veka: monografiya [Theory of judicial administration in Russia in the second half of the twentieth century]. In: Upravlenie $v$ pravookhranitel'noy sfere: traektoriya razvitiya [Management in the law enforcement sphere: trajectory of development]. Chelyabinsk, 2019, pp. 6-23.

\footnotetext{
ALEKSANDR A. KABURKIN - Post-Graduate Student, Russian History Department, Chuvash State University, Russia, Cheboksary (kaa21.777@yandex.ru; ORCID: https://orcid.org/0000-0002-4597-7996).
}

Формат цитирования: Кабуркин А.А. Суды Ханты-Мансийского автономного округа в первый год послевоенной пятилетки // Исторический поиск. - 2021. - Т. 2, № 2. - C. 13-20. DOI: 10.47026/2712-9454-2021-22-13-20. 